\title{
Fracionamento do extrato diclorometânico de Senecio desiderabilis Vellozo e avaliação da atividade antimicrobiana
}

\author{
Régis A. N. Deuschle ${ }^{1}$ Tarcisio de Camargo ${ }^{2}$, Sydney H. Alves ${ }^{1,3}$, Carlos A. Mallmann, \\ Berta M. Heizmann ${ }^{1,5 *}$ \\ ${ }^{1}$ Programa de Pós-Graduação em Ciência e Tecnologia Farmacêuticas, Universidade Federal de Santa Maria, \\ Campus Universitário, 97105-900, Santa Maria, RS, Brasil, \\ ${ }^{2}$ Curso de Graduação em Farmácia, Universidade Federal de Santa Maria, Campus Universitário, \\ 97105-900, Santa Maria, RS, Brasil, \\ ${ }^{3}$ Departamento de Microbiologia e Parasitologia, Universidade Federal de Santa Maria, \\ Campus Universitário, 97105-900, Santa Maria, RS, Brasil, \\ ${ }^{4}$ Departamento de Medicina Veterinária Preventiva, Universidade Federal de Santa Maria, \\ Campus Universitário, 97105-900, Santa Maria, RS, Brasil, \\ ${ }^{5}$ Departamento de Farmácia Industrial, Universidade Federal de Santa Maria, \\ Campus Universitário, 97105-900, Santa Maria, RS, Brasil
}

\begin{abstract}
RESUMO: O presente trabalho descreve a avaliação da atividade antimicrobiana de uma fração sesquiterpênica, obtida a partir do extrato $\mathrm{CH}_{2} \mathrm{Cl}_{2}$ de Senecio desiderabilis Vellozo (Asteraceae), e do germacreno D, isolado a partir desta. A fração e o germacreno D foram obtidos mediante cromatografia em coluna e analisados por CG-EM e também por RMN, no caso da substância isolada. A atividade antimicrobiana foi avaliada frente a leveduras e bactérias pelo método de microdiluição em caldo, conforme preconizado pelo NCCLS, nos documentos M27-A2 para fungos leveduriformes, e M7-A4 para bactérias. A fração sesquiterpênica evidenciou moderada atividade antimicrobiana, enquanto que o germacreno D não inibiu o crescimento dos microrganismos testados.
\end{abstract}

Unitermos: Senecio desiderabilis, Asteraceae, atividade antimicrobiana, sesquiterpeno, germacreno D.

\begin{abstract}
Fractionation of dichlorometane extract from Senecio desiderabilis Vellozo and evaluation of the antimicrobial activity" The present work describes the evaluation of the antimicrobial activity of a sesquiterpene fraction obtained from $\mathrm{CH}_{2} \mathrm{Cl}_{2}$ extract of Senecio desiderabilis Vellozo (Asteraceae), and of germacrene D isolated from it. The sesquiterpene fraction and the isolated substance were obtained by column chromatography and analysed by GC-MS. Substance identification was carried out by NMR. The antimicrobial activity was assayed by broth microdilution method, as preconized by NCCLS in the documents M27-A for yeasts and M7-A4 for bacteria. The sesquiterpene fraction showed moderated antimicrobial activity, and germacrene D did not inhibit the tested microorganisms.
\end{abstract}

Keywords: Senecio desiderabilis, Asteraceae, antimicrobial activity, sesquiterpene, germacrene D.

\section{INTRODUÇÃO}

Várias espécies de Senecio apresentam atividade antimicrobiana descrita na literatura (Pérez et al., 1999; Cos et al., 2002; Rojas et al., 2003; Lima et al., 2006), sendo empregadas devido a esta propriedade na medicina popular de diversos países, inclusive na América Latina (Abdo et al., 1992; Portillo et al., 2001). Uma dessas espécies, Senecio brasiliensis (Spreng.) Less, está incluída na primeira edição da Farmacopéia Brasileira (Brandão et al., 2006)

Em estudo prévio realizado por Deuschle et al. (2006), foi descrita a avaliação da atividade antimicrobiana dos extratos diclorometânico e etanólico das partes aéreas de Senecio desiderabilis Vellozo (Asteraceae), sendo que o primeiro apresentou-se mais ativo contra as cepas bacterianas e fúngicas ensaiadas.

Este trabalho descreve o fracionamento do extrato diclorometânico de $S$. desiderabilis e a avaliação da atividade antimicrobiana da principal fração obtida, objetivando o isolamento e a identificação da(s) substância(s) ativa(s).

\section{MATERIAL E MÉTODOS}

\section{Material vegetal}


As partes aéreas de $S$. desiderabilis Vellozo foram coletadas pelo botânico Marcos Sobral (Faculdade de Farmácia da UFMG), em São José dos Ausentes, RS, Brasil, em fevereiro de 2002. Material testemunha encontra-se depositado no herbário do Departamento de Biologia da UFSM, sob o número SMDB 8936.

\section{Extração}

O material vegetal fresco $(645,4 \mathrm{~g})$ foi grosseiramente dividido e extraído por maceração em $\mathrm{CH}_{2} \mathrm{Cl}_{2}$ por 8 dias. O procedimento foi repetido, reunindose os extratos obtidos que, após a concentração em evaporador rotatório, forneceram 42,65 g de um resíduo pastoso.

\section{Obtenção da fração sesquiterpênica e isolamento do germacreno D}

O extrato diclorometânico (38 g) foi cromatografado em coluna flash $(27 \times 3,1 \mathrm{~cm})$ sobre gel de sílica $60(63-230 \mu \mathrm{m})$, tendo $\mathrm{CH}_{2} \mathrm{Cl}_{2}$ como eluente $(2,5 \mathrm{~L})$. Das 25 frações de $100 \mathrm{~mL}$ obtidas, as frações 2-5 (13,99 g) foram fracionadas sobre coluna contendo $84 \mathrm{~g}$ de gel de sílica $(25,5 \times 3,1 \mathrm{~cm})$ com $\mathrm{CH}_{2} \mathrm{Cl}_{2}$. Foram obtidas 25 frações de $100 \mathrm{~mL} .927 \mathrm{mg}$ das frações 1-2 da coluna anterior foram separados sobre coluna de gel de sílica (210 g, 55,5 x 3,2 cm), tendo hexano como eluente. Foram recolhidas 41 frações de $10 \mathrm{~mL}$. As frações 1-30 da última coluna (141,1 mg), foram caracterizadas como uma mistura de sesquiterpenóides através da análise por CCD e CG-EM e tiveram sua atividade antimicrobiana avaliada. A fração 1 (5,74 g), obtida da coluna flash, foi fracionada sobre coluna de gel de sílica (60 g, 18 x 3,1 $\mathrm{cm}$ ), uma vez que mostrou semelhança com as frações 12 (927 mg), obtidas da segunda coluna. Foram recolhidas 25 frações de $10 \mathrm{~mL}$. $748 \mathrm{mg}$ das frações 1-15 da coluna anterior, constituídos pela mistura de sesquiterpenóides com atividade antimicrobiana, foram cromatografadas sobre $74 \mathrm{~g}$ de gel de sílica (54 x 2,4 cm) impregnado com $\mathrm{AgNO}_{3} 10$ \% (Stahl, 1969) tendo hexano:acetona (98:2) como eluente. Das 92 frações de $5 \mathrm{~mL}$ obtidas, as frações 64-92 (180 mg), constituídas por uma única substância, foram analisadas por CG-EM, ${ }^{1} \mathrm{H} \mathrm{e}{ }^{13} \mathrm{C}$ RMN (BRUCKER DPX, ${ }^{1} \mathrm{H}: 400 \mathrm{MHz} ;{ }^{13} \mathrm{C}$ : $100 \mathrm{MHz}$, em $\mathrm{CDCl}_{3}$ ).

CG-EM: AGILENT 6890, com detector de massas série 5973; split inlet 1:100, gás carreador: hélio (1 mL/min); coluna capilar de sílica fundida HP5MS (Hewlett Packard, $5 \%$ fenilmetilsiloxano, $30 \mathrm{~m}$ de comprimento, 0,25 mm Ø, espessura do filme: 0,25 $\mu \mathrm{m}$ ); Programa de análise: $40^{\circ} \mathrm{C}$ (Ti) por $4 \mathrm{~min}, 40-260^{\circ} \mathrm{C}$, $4{ }^{\circ} \mathrm{C} / \mathrm{min}$; temperatura do injetor: $220^{\circ} \mathrm{C}$; energia de ionização 70 eV; banco de dados NIST, 1998.

Germacreno D: óleo incolor; $\mathrm{R}_{\mathrm{f}}$ 0,20 (gel de sílica $\mathrm{F}_{254}$ impregnado com $\mathrm{AgNO}_{3} 10 \%$; hexano:éter etílico 98:2, 3 desenvolvimentos; visualização após nebulização com anisaldeído- $\mathrm{H}_{2} \mathrm{SO}_{4}$ ); TR (CG): 30,94 min.; RMN-1 ${ }^{1}$ : $\delta(p p m)=5,80(1 \mathrm{H}, \mathrm{d}, \mathrm{J} 15,8 \mathrm{~Hz}, \mathrm{H}-5)$, 5,27 (1H, dd, J 15,8 e 9,9 Hz, H-6), 5,16 (1H, dd, J 11,2 e 4,5 Hz, H-1), 4,82 (1H, d, J 2,24 Hz, H-15a), 4,76 (1H, d, J 1,64 Hz, H-15b), 2,43 (1H, m, H-3a), 2,34 (1H, m, H-2a), 2,11 (2H, m, 9-H), 2,04 (1H, m, H-3b), 2,01 (1H, m, H-7), 1,98 (1H, m, H-2b), 1,54 (3H, s, Me-14), 1,48 (2H, m, H-8), 1,43 (1H, m, 11-H), 0,90 (3H, d, J 6,72 Hz, Me-12), 0,84 (3H, d, J 6,8 Hz, Me-13). RMN- ${ }^{13} \mathrm{C}$ (ppm): $\delta=140,9$ (C4), 135,6 (C5), 133,4 (C6), 129,7 (C1), 128,7 (C10), 109,0 (C15), 53,0 (C7), 40,8 (C9), 34,5 (C3), 32,8 (C11), 29,3 (C2), 26,5 (C8), 20,8 (C13), 19,3 (C12), 15,9 (C14). MS: $\mathrm{m} / \mathrm{z}$ (\%): 204 (17) $\left[\mathrm{M}^{+}\right], 161$ (100) $\left[\mathrm{M}-\mathrm{C}_{3} \mathrm{H}_{7}\right]$, 147 (65), 133 (25), 119 (61), 105 (78), 91 (68), 79 (42), 67 (21), 55 (24), 41 (62), 27 (32), 15 (4).

\section{Microrganismos}

Foram utilizados microrganismos catalogados em coleções (cepas tipificadas) conforme especificado na tabela 1.

\section{Preparação das amostras para o ensaio}

A fração sesquiterpênica e a substância isolada foram solubilizadas inicialmente em Tween 80:meio de cultura (1:20), de forma a obter-se uma solução-estoque. As concentrações intermediárias foram preparadas diluindo-se a solução-estoque no meio apropriado, de forma a resultar em concentrações finais de 5000, 2500, $1000,500,250,50$ e $25 \mu \mathrm{g} / \mathrm{mL}$. Para estudo da atividade antifúngica, volumes de $100 \mu \mathrm{L}$ das concentrações intermediárias foram depositados nas cavidades de uma microplaca estéril; a seguir foram agregados volumes de $100 \mu \mathrm{L}$ do inóculo padronizado. Para avaliação da atividade antibacteriana, volumes de $200 \mu \mathrm{L}$ da concentração final de cada amostra foram depositados nas cavidades de uma placa de microtitulação e, então, $10 \mu \mathrm{L}$ do inóculo padronizado foram adicionados.

\section{Avaliação da atividade antimicrobiana}

A atividade antimicrobiana foi avaliada através da técnica de microdiluição em caldo, com base nos documentos M27-A2 (NCCLS, 2002) para fungos leveduriformes e M7-A4 (NCCLS, 1997) para bactérias.

Previamente aos testes, os cultivos bacterianos foram ativados através de subcultivos em ágar MullerHinton durante $24 \mathrm{~h}$ a $35{ }^{\circ} \mathrm{C}$, enquanto que os fungos foram subcultivados em ágar Sabouraud dextrose 48 $\mathrm{h} / 30-35^{\circ} \mathrm{C}$

Após a ativação, padronizou-se o inóculo, que consistiu na preparação de uma suspensão bacteriana em salina, com turvação similar ao tubo 0,5 da Escala Mac Farland ( $\left.1 \times 10^{8} \mathrm{UFC} / \mathrm{mL}\right)$. A seguir, esta suspensão foi diluída a 1:100 (1 x 10 $\left.10^{7} \mathrm{UFC} / \mathrm{mL}\right)$ em salina estéril, e volumes de $10 \mu \mathrm{L}$ foram então transferidos para as cavidades de uma placa de microtitulação, contendo 
$200 \mu \mathrm{L}$ do caldo Muller-Hinton acrescido de diferentes concentrações da fração sesquiterpênica/substância isolada, resultando num inóculo final de $2 \times 10^{5}$ a $5 \times 10^{5}$ $\mathrm{UFC} / \mathrm{mL}$. As placas com patógenos bacterianos foram incubadas a $37^{\circ} \mathrm{C} / 24 \mathrm{~h}$. A suspensão de microrganismos leveduriformes foi preparada de modo similar. Após a padronização da turvação (equivalente ao tubo 0,5 da escala Mac Farland), foram preparadas diluições sucessivas de 1:50 e 1:20 no caldo RPMI 1640 tamponado. As placas foram incubadas a $35^{\circ} \mathrm{C} / 48 \mathrm{~h}$.

As concentrações inibitórias mínimas (CIMs) foram definidas como a menor concentração capaz de inibir completamente o crescimento microbiano.

\section{RESULTADOS E DISCUSSÃO}

A caracterização cromatográfica das frações 1-30 por CG-EM indicou serem estas compostas por uma mistura de 11 substâncias majoritárias, todos hidrocarbonetos de estrutura sesquiterpênica, com massa molecular variando entre 202 e 204 u.m.a. O germacreno D, identificado por comparação de seus dados espectroscópicos com a literatura (Steliopoulos et al., 2002), aparecia na percentagem de $14 \%$. Portanto, as frações 1-30 são formadas basicamente de compostos que, com freqüência, aparecem como constituintes dos óleos voláteis de diferentes espécies vegetais. A atividade antimicrobiana dos óleos e de alguns de seus componentes já está bem estabelecida. Estes freqüentemente apresentam a propriedade de inibir o crescimento de bactérias e fungos, uma vez que servem de defesa contra $\mathrm{o}$ ataque de microrganismos nos vegetais (Magwa et al., 2006; Skocibušic et al., 2006). A literatura também traz estudos que evidenciam a atividade antimicrobiana de óleos essenciais de espécies de Senecio (Pérez et al., 1999; Francescato et al., 2006; Murari et al., 2006).

Os resultados dos testes para a avaliação da atividade antimicrobiana encontram-se na tabela 1 .

A comparação dos resultados para a fração sesquiterpênica com os dados correspondentes para o extrato diclorometânico evidenciam um aumento inespecífico da atividade antimicrobiana, já que a fração

Tabela 1. Atividade antimicrobiana da fração sesquiterpênica, do germacreno D e do extrato diclorometânico bruto de Senecio desiderabilis.

\begin{tabular}{|c|c|c|c|}
\hline Microrganismos & $\begin{array}{c}\text { CIM }(\mu \mathrm{g} / \mathrm{mL}) \\
\text { Fração sesquiterpênica }\end{array}$ & $\begin{array}{l}\mathrm{CIM}(\mu \mathrm{g} / \mathrm{mL}) \\
\text { germacreno D }\end{array}$ & $\begin{array}{c}\mathrm{CIM}(\mu \mathrm{g} / \mathrm{mL}) \\
\text { Extrato } \mathrm{CH}_{2} \mathrm{Cl}_{2} \\
\text { (Deuschle et al., 2006) }\end{array}$ \\
\hline Candida albicans ATCC 44373 & 500 & - & 2500 \\
\hline Candida dubliniensis BRCD 12 & 500 & - & 500 \\
\hline Candida krusei FM USP 1023 & 250 & - & 250 \\
\hline Saccharomyces cerevisiae ATCC 2601 & - & - & 25 \\
\hline Micrococcus luteus ATCC 10240 & 250 & - & 500 \\
\hline Escherichia coli ATCC 25922 & 1000 & - & - \\
\hline
\end{tabular}

- Ausência de atividade

apresentou uma maior atividade frente a uma levedura ( $C$. albicans), uma bactéria Gram-positiva (M. luteus) e um bacilo Gram-negativo (E. coli). Estes resultados indicam uma possível concentração das substâncias ativas na fração sesquiterpênica, frente a estes microrganismos. Os dados obtidos estão de acordo com os relatos encontrados na literatura, que descrevem a atividade antimicrobiana de várias misturas de sesquiterpenóides contra diferentes microrganimos (Burt, 2004, Pérez et al., 1999, Skocibušic et al., 2006.). Também é possível que uma ou mais substâncias ativas tenham sua atividade antagonizada no extrato bruto. Os resultados indicam uma maior atividade da fração sesquiterpênica sobre microrganismos Gram-positivos, em comparação com Gram-negativos e confirmam as informações contidas na literatura (Burt, 2004). Segundo Holley \& Patel (2005), a membrana dual apresentada pelas bactérias Gram-negativas forma um envelope complexo e parece oferecer proteção, sendo considerada responsável pela menor suscetibilidade destes microrganismos frente aos óleos essenciais. Curiosamente a fração sesquiterpênica não inibiu o crecimento $S$. cerevisiae, ao contrário do que foi observado para o extrato diclorometânico desta espécie (Deuschle et al., 2006), o que indica que a(s) substância(s) responsável(eis) por esta atividade não está(ão) presente(s) nesta fração. É possível que esta atividade seja devido à presença de alcalóides pirrolizidínicos, constituintes comuns em espécies de Senecio, cuja atividade antifúngica pode ser explicada pela lesão do DNA (Prakash et al., 1999).

De acordo com Burt (2004), os óleos essenciais compreendem um grande número de componentes e seu modo de ação envolve vários alvos na célula bacteriana. A maioria dos autores consideram a lipofilia de seus constituintes como a propriedade que explicaria a atividade antimicrobiana, característica que permitiria a partição destes compostos nos lipídeos da membrana celular e da mitocôndria, aumentando sua permeabilidade e levando ao extravazamento do conteúdo celular (Cowan, 1999). No entanto, este parece não ser o único mecanismo envolvido na atividade antimicrobiana dos óleos essenciais, uma vez que o germacreno $\mathrm{D}$, por ser um hidrocarboneto, apresenta características lipofílicas acentuadas e não inibiu o crescimento microbiano até a 
concentração de $5000 \mu \mathrm{g} / \mathrm{mL}$.

Segundo outros autores, componentes dos óleos essenciais também podem agir sobre proteínas celulares localizadas nas membranas citoplasmáticas, entre elas as ATPases, através de sua acumulação na dupla camada lipídica e conseqüente destruição da interação lipídeoproteína. Alternativamente, é possível uma interação direta de compostos lipofílicos com porções hidrofóbicas das proteínas (Juven et al., 1994; Sikkema et al., 1995). Entretanto, devido ao grande número de diferentes grupos químicos presentes nos óleos essenciais, é provável que sua atividade antimicrobiana não possa ser atribuída a um mecanismo de ação específico (Skandamis; Nychas, 2001; Carson et al., 2002).

\section{AGRADECIMENTOS}

Ao botânico Marcos Sobral, pela localização, identificação e coleta do material vegetal. Ao CNPq pelo apoio financeiro.

\section{REFERÊNCIAS}

Abdo S, de Bernardi M, Marinoni G, Mellerio G, Samaniego S, Vidarit G, Vita Finzit P 1992. Furanoeremophilanes and other constituents from Senecio canescens. Phytochemistry 31: 3937-3941.

Brandão MGL, Cosenza GP, Moreira RA, Monte-Mor RLM 2006. Medicinal plants and other botanical products from the Brazilian Official Pharmacopoeia. Rev Bras Farmacogn 16: 408-420.

Burt S 2004. Essential oils: their antibacterial properties and potential applications in foods - a review. Int J Food Microbiol 94: 223-253.

Carson CF, Mee BJ, Riley TV 2002. Mechanism of action of Melaleuca alternifolia (tea tree) oil on Staphylococcus aureus determined by time-kill, lysis, leakage and salt tolerance assays and electron microscopy. Antimicrob Agents Chemother 46: 1914-1920.

Cos P, Hermans N, De Bruyne T, Apers S, Sindambiwe JB, Vanden Berghe D, Pieters L, Vlietinck AJ 2002. Further evaluation of Rwandan medicinal plant extracts for their antimicrobial and antiviral activities. J Ethnopharmacol 79: 155-163.

Cowan MM 1999. Plant products as antimicrobial agents. Clin Microbiol Rev 12: 564-582.

Deuschle RAN, Camargo T, Francescato LN, Alves SH, Heinzmann BM 2006. Antimicrobial activity of Senecio desiderabilis Vellozo (Compositae). Acta Farm Bonaerense 25: 356-359.

Francescato L, Silva GLS, Pozzatti P, Alves SH, Heinzmann BM 2006. Atividade antimicrobiana dos óleos essenciais de S. heterotrichius, S. ceratophylloides, S. oxyphyllus e S. leptolobus. V Jornada Catarinense / I Jornada Internacional de Plantas Medicinais. Joinvile, Brasil.

Holley RA, Patel D 2005. Improvement in shelf-life and safety of perishable foods by plant essential oils and smoke antimicrobials. Food Microbiol 22: 273-292.

Juven BJ, Kanner J, Schved F, Weisslowicz H 1994. Factors that interact with the antibacterial action of thyme essential oil and its active constituents. J Appl Bacteriol 76: 626-631.

Lima MRF, Ximenes CPA, Luna JS, Sant’Ana AEG 2006. The antibiotic activity of some Brazilian medicinal plants. Rev Bras Farmacogn 16: 300-306.

Magwa ML, Gundidza M, Gweru N, Humphrey G 2006. Chemical composition and biological activities of essential oil from the leaves of Sesuvium portulacastrum. J Ethnopharmacol 103: 85-89.

Murari AM, Hörner R, Michelot TM, Heldwein CG, Heinzmann BM 2006. Atividade antibacteriana do óleo essencial de Senecio crassiflorus (Poir.) DC. var. crassiflorus. V Jornada Catarinense / I Jornada Internacional de Plantas Medicinais. Joinvile, Brasil.

NCCLS 2002. National Comittee for Clinical Laboratory Standards. Reference method for broth dilution antifungal suceptibility testing of yeasts. Approved standard document M27-A2.

NCCLS 1997. National Comittee for Clinical Laboratory Standards. Methods for dilution antimicrobial susceptibility tests for bacteria that grow aerobically. 5th ed. Approved standard document M7-A4, Wayne, P.A.

Prakash AS, Pereira TN, Reilly PEB, Seawright AA 1999. Pyrrolizidine alkaloids in human diet. Mutat Res Genet Toxicol Environ Mutagen 443: 53-67.

Pérez C, Agnese AM, Cabrera JL 1999. The essential oil of Senecio graveolens (Compositae): chemical composition and antimicrobial activity tests. $J$ Ethnopharmacol 66: 91-96.

Portillo A, Vila R, Freixa B, Adzet T, Cañigueral S 2001. Antifungal activity of Paraguayan plants used in traditional medicine. J Ethnopharmacol 76: 93-98.

Rojas R, Bustamante B, Bauer J, Fernandez I, Alban J, Lock O 2003. Antimicrobial activity of selected Peruvian plants. J Ethnopharmacol 88: 199-204.

Sikkema J, De Bont JAM, Poolman B 1995. Mechanisms of membrane toxicity of hydrocarbons. Microbiol Rev 59: 201-222.

Skandamis PN, Nychas GJE 2001. Effect of oregano essential oil on microbiological and physico-chemical attributes of minced meat stored in air and modified atmospheres. J Appl Microbiol 91: 1011-1022.

Skocibušic M, Bezic N, Dunkic V 2006. Phytochemical composition and antimicrobial activities of the essential oils from Satureja subspicata Vis. growing in Croatia. Food Chem 96: 20-28.

Stahl E 1969. Thin-layer chromatography - a laboratory handbook. Berlin: Springer. p. 397.

Steliopoulos P, Wüst M, Adam KP, Mosandl A 2002. Biosynthesis of the sesquiterpene germacrene $\mathrm{D}$ in Solidago canadensis: ${ }^{13} \mathrm{C}$ and ${ }^{2} \mathrm{H}$ labeling studies. Phytochemistry 60: 13-20. 